\title{
Global gene expression analysis combined with a genomics approach for the identification of signal transduction networks involved in postnatal mouse myocardial proliferation and development
}

\author{
RUOXIN WANG ${ }^{1,2}$, CHAO SU $^{3,4}$, XINTING WANG ${ }^{3,4}$, QIANG FU $^{1}$, XINGJIE GAO ${ }^{3,4}$, \\ CHUNYAN ZHANG ${ }^{3,4}$, JIE YANG ${ }^{2-5}$, XI YANG $^{2}$ and MINXIN WEI ${ }^{1,6}$

\begin{abstract}
${ }^{1}$ Department of Cardiovascular Surgery, Tianjin Medical University General Hospital, Tianjin 300070, P.R. China; ${ }^{2}$ Department of Immunology, University of Manitoba, Winnipeg, MB R3E 0T5, Canada; ${ }^{3}$ Department of Biochemistry and Molecular Biology, Department of Immunology, School of Basic Medical Sciences; ${ }^{4}$ Tianjin Key Laboratory of Cellular and Molecular Immunology; ${ }^{5}$ Laboratory of Molecular Immunology, Research Center of Basic Medical Science, Tianjin Medical University, Tianjin 300070; ${ }^{6}$ Department of Cardiovascular Surgery, Shenzhen Sun Yat-sen Cardiovascular Hospital, Shenzhen, Guangdong 518001, P.R. China
\end{abstract}

Received January 23, 2017; Accepted October 26, 2017

DOI: $10.3892 /$ ijmm.2017.3234

\begin{abstract}
Mammalian cardiomyocytes may permanently lose their ability to proliferate after birth. Therefore, studying the proliferation and growth arrest of cardiomyocytes during the postnatal period may enhance the current understanding regarding this molecular mechanism. The present study identified the differentially expressed genes in hearts obtained from 24 h-old mice, which contain proliferative cardiomyocytes; 7-day-old mice, in which the cardiomyocytes are undergoing a proliferative burst; and 10-week-old mice, which contain growth-arrested cardiomyocytes, using global gene expression analysis. Furthermore, myocardial proliferation and growth arrest were analyzed from numerous perspectives, including Gene Ontology annotation, cluster analysis, pathway enrichment and network construction. The results of a Gene Ontology analysis indicated that, with increasing age, enriched gene function was not only associated with cell cycle, cell division and mitosis, but was also associated with metabolic processes and protein synthesis. In the pathway analysis, 'cell cycle', proliferation pathways, such as the 'PI3K-AKT signaling pathway', and 'metabolic pathways' were well represented. Notably, the cluster analysis revealed that bone morphogenetic protein (BMP)1, BMP10, cyclin E2, E2F transcription factor 1 and insulin like growth factor 1 exhibited increased expression in hearts obtained from 7-day-old mice.
\end{abstract}

Correspondence to: Dr Minxin Wei, Department of Cardiovascular Surgery, Shenzhen Sun Yat-sen Cardiovascular Hospital, 1021 Dongmenbei Road, Luohu, Shenzhen, Guangdong 518001, P.R. China

E-mail: minxinw@126.com

Key words: cardiomyocyte, gene expression profile, signal transduction pathway, cell cycle, C57BL/6 mice
In addition, the signal transduction pathway associated with the cell cycle was identified. The present study primarily focused on genes with altered expression, including downregulated anaphase promoting complex subunit 1 , cell division cycle (CDC20), cyclin dependent kinase 1, MYC proto-oncogene, bHLH transcription factor and $C D C 25 C$, and upregulated growth arrest and DNA damage inducible $\alpha$ in 10-week group, which may serve important roles in postnatal myocardial cell cycle arrest. In conclusion, these data may provide important information regarding myocardial proliferation and development.

\section{Introduction}

Myocardial infarction is one of the most prevalent medical conditions worldwide (1). Pathological damage caused by myocardial infarction often results in irreversible injury to myocardial cells (2). This damage grossly affects cardiac function, due to the markedly decreased number of cardiomyocytes. The low capacity of adult cardiomyocytes to undergo proliferation and differentiation is the main reason why myocardial infarction cannot be repaired. The concept that hypertrophy, but not proliferation, of cardiomyocytes occurs under some pathophysiological conditions after birth has long been accepted (3). However, recent evidence has challenged this notion. Poss et al investigated myocardial generative capacity using a ventricular resection model, and observed that adult myocardial proliferation may exist in adult teleosts, including zebrafish (4). In addition, Porrello et al reported that excising partial cardiomyocytes at the apical portion of the heart in 24-h-old mice could stimulate cardiomyocytes to repair the damaged region (5), whereas Naqvi et al demonstrated that a surge of thyroid hormones during preadolescence may serve an important role in myocardial proliferation (6). These phenomena indicate that adult mammalian myocardial proliferation may be driven through physiological or pathological stimulation. 
Furthermore, Mollova et al observed that cardiomyocytes exhibited increased proliferative potential in 10-year-old children compared with in adults (7). Therefore, analyzing and investigating the gene expression profile of cardiomyocytes in the postnatal period may enhance our current understanding of the molecular mechanisms underlying the limited proliferative capacity of cardiomyocytes in myocardial growth arrest.

Gan et al conducted an integrative analysis of the developing postnatal mouse heart transcriptome by comparing 2- and 13-day-old postnatal mouse hearts (8), which reflect the dividing and growth-arresting phases of cardiomyocytes, respectively. The results revealed that GATA binding protein 4 , myosin heavy chain 7 and insulin like growth factor 1 receptor $(I G F 1 R)$ may act on the gene interaction network, whereas taspase 1, transducer of ERBB2, 1, chromosome 1 open reading frame 61 , allograft inflammatory factor 1 , Rho associated coiled-coil containing protein kinase 1 , trefoil factor 2 and microRNA-503-5p were the key drivers inhibiting cardiomyocyte proliferation. Another study by Naqvi et al reported that mice exhibited a burst of cardiomyocyte proliferation during early preadolescent development, between 7 and 15 days of life, which was regulated by the thyroid hormone/IGF1/IGF1R/protein kinase B (AKT) pathway (6). Therefore, based on the physiological characteristics of mouse cardiomyocytes, 13-day-old mice may not fully reflect either the growth-arrested stage or the proliferative burst phase. To better elucidate the mechanisms and pathways involved in myocardial growth and arrest, the present study analyzed the differentially expressed genes in mouse hearts obtained from 24-h-old mice, which contain proliferative cardiomyocytes $(5,6)$; 7-day-old mice, in which cardiomyocytes are undergoing a proliferative burst (6); and 10-week-old mice, which contain growth-arrested cardiomyocytes (6).

Furthermore, Gene Ontology (GO) annotation, pathway enrichment and series test of cluster (STC) were conducted to investigate the proliferative and growth-arresting phases of cardiomyocytes from numerous perspectives. Furthermore, the signal transduction pathway associated with the cell cycle was identified, in order to characterize the network involved in the phenomenon of myocardial cell cycle arrest. Elucidating the molecular-genetic alterations involved in the proliferative, proliferative burst and growth-arrest phases of cardiomyocytes may enable the identification of potential signaling factors that can induce the regeneration of cardiomyocytes in heart disease.

\section{Materials and methods}

Animal sample collection. Pregnant C57BL/6 mice ( $\mathrm{n}=9$; age, 10-11 weeks; weight, 25-30 g) were purchased from the National Institutes for Food and Drug Control (Beijing, China) and were quality inspected by the National Quality Inspection Center of Experimental Animals (Beijing, China). All mice were maintained at $22^{\circ} \mathrm{C}$ and $55 \%$ relative humidity under a 12-h light/dark cycle with free access to normal food and water. Mice were maintained according to the protocols of the National Science Council of the People's Republic of China (Beijing, China). In the present study, all of the mice used at $24 \mathrm{~h}(\mathrm{n}=9$; weight, 1-2 g) and 7 days ( $\mathrm{n}=9$; weight, 3.5-5 g) of age were delivered from 9 pregnant mice (10-week group) through eutocia. Each time-point included three parallel samples, and each sample consisted of three mouse hearts. The 18 hearts from 24-h- and 7-day-old mice were obtained from the 910 -week-old pregnant mice. The mice were sacrificed by cervical dislocation following mild sedation with isoflurane. Whole hearts were harvested from 24-h-old, 7-day-old and 10-week-old mice. Ventricular myocardial samples were immediately dissected from the whole hearts for total RNA isolation following several washes with D-Hanks solution. The present study was approved by the Tianjin Medical University Animal Care and Use Committee (Tianjin, China), and all animal experiments were performed according to the Guidelines for Animal Experiments of the Tianjin Medical University, 2014 revision.

Total RNA isolation and gene expression analysis by microarray. RNA was extracted from the cardiac tissues using TRIzol $^{\circledR}$ reagent (Invitrogen; Thermo Fisher Scientific, Inc., Waltham, MA, USA), according to the manufacturer's protocol, and subsequent purification was conducted using an RNeasy kit (Qiagen Sciences, Inc., Germantown, MD, USA). cDNA was generated using One-Cycle Target labeling and control reagents (first-strand cDNA was incubated in the thermocycler at $25^{\circ} \mathrm{C}$ for $1 \mathrm{~h}, 42^{\circ} \mathrm{C}$ for $1 \mathrm{~h}, 4^{\circ} \mathrm{C}$ for $2 \mathrm{~min}$; second-strand cDNA was incubated in the thermocycler at $16^{\circ} \mathrm{C}$ for $1 \mathrm{~h}, 65^{\circ} \mathrm{C}$ for $1 \mathrm{~min}$, $4^{\circ} \mathrm{C}$ for $2 \mathrm{~min}$ ), and cRNA was generated using a GeneChip IVT labeling kit (both Affymetrix; Thermo Fisher Scientific, Inc.). Biotin-labeled, fragmented ( $\leq 200 \mathrm{nt}) \mathrm{cRNA}$ was hybridized for $16 \mathrm{~h}$ at $45^{\circ} \mathrm{C}$ to Affymetrix GeneChip Mouse Gene 2.0 arrays (Affymetrix; Thermo Fisher Scientific, Inc.). The GeneChips were washed and stained using the Affymetrix Fluidics Station 450 (Affymetrix; Thermo Fisher Scientific, Inc.), and were scanned using Affymetrix ${ }^{\circledR}$ GeneChip Command Console, installed in the GeneChip ${ }^{\circledR}$ Scanner 3000 7G (Affymetrix; Thermo Fisher Scientific, Inc.). The data were analyzed with the Robust Multichip Analysis (RMA) algorithm using Affymetrix default analysis settings and global scaling as the normalization method. Values are presented as $\log 2$ RMA signal intensity.

Reverse transcription-quantitative polymerase chain reaction $(R T-q P C R)$. RT-qPCR was used to verify microarray results using the same RNA samples as used for the microarray analyses. The primer sequences used in the present study are listed in Table I. Briefly, total purified RNA was reverse-transcribed using the SuperScript III First-Strand Synthesis system (Invitrogen; Thermo Fisher Scientific, Inc.). RNA was incubated in the thermocycler at $44^{\circ} \mathrm{C}$ for $1 \mathrm{~h}, 92^{\circ} \mathrm{C}$ for $10 \mathrm{~min}$ to inactivate the reverse transcriptase. RT-qPCR was performed using SYBR-Green PCR mix and was run on the ABI 7300 Real-Time PCR system (both Applied Biosystems; Thermo Fisher Scientific, Inc.). The reactions were performed in triplicate in a total volume of $25 \mu 1$. The cycling conditions consisted of an initial, single cycle of $5 \mathrm{~min}$ at $95^{\circ} \mathrm{C}$, followed by 40 cycles of $30 \mathrm{sec}$ at $95^{\circ} \mathrm{C}, 30 \mathrm{sec}$ at $54^{\circ} \mathrm{C}$, $15 \mathrm{sec}$ at $72^{\circ} \mathrm{C}$, and fluorescence acquisition at $83^{\circ} \mathrm{C}$ for $1 \mathrm{sec} . \mathrm{A}$ melting curve analysis $\left(60-95^{\circ} \mathrm{C}\right)$ was used to assess amplification specificity. The relative expression levels of each gene were determined using the $2^{-\Delta \Delta \mathrm{Cq}}$ method (9). Statistical analyses were performed as described for the microarray data. Pearson's correlation coefficient was further calculated for each gene using the normalized data to quantify the consistency between microarray experiments and RT-qPCR $(\mathrm{P}<0.05$ and $\mathrm{R}>0.9)$. 
Table I. Primer sequences.

\begin{tabular}{|c|c|}
\hline Gene & Primer sequence ( $5^{\prime}$ to $\left.3^{\prime}\right)$ \\
\hline$B M P 1$ & $\begin{array}{l}\text { F: ATCCAGGTGTCTGAGGGTTTCC } \\
\text { R: GACTTCCAGGTAGTCGTAGGCA }\end{array}$ \\
\hline CCNE2 & $\begin{array}{l}\text { F: GTACTGTCTGGAGGAATCAGCC } \\
\text { R: CCAAACCTCCTGTGAACATGCC }\end{array}$ \\
\hline$I G F 1$ & $\begin{array}{l}\text { F: GTGGATGCTCTTCAGTTCGTGTG } \\
\text { R: TCCAGTCTCCTCAGATCACAGC }\end{array}$ \\
\hline$C D C 20$ & $\begin{array}{l}\text { F: GATGGACGACATCTGGCAAGTG } \\
\text { R: GTTGCCAGGATATTGGACTGCC }\end{array}$ \\
\hline$P L K 1$ & $\begin{array}{l}\text { F: CCATCTTCTGGGTCAGCAAGTG } \\
\text { R: CCGTCATTGTAGAGAATCAGGCG }\end{array}$ \\
\hline$C D C 25 C$ & $\begin{array}{l}\text { F: AACTCCACGACTCGGCAAACCT } \\
\text { R: GTAGTAAGCGGAGAGGCAGACA }\end{array}$ \\
\hline$M Y C$ & $\begin{array}{l}\text { F: TCGCTGCTGTCCTCCGAGTCC } \\
\text { R: GGTTTGCCTCTTCTCCACAGAC }\end{array}$ \\
\hline CCNG1 & $\begin{array}{l}\text { F: GCGTTGGAGATCCAAGCACTGA } \\
\text { R: GGAAACAAGCTCTTGCCAGAAGG }\end{array}$ \\
\hline$F G F 1$ & $\begin{array}{l}\text { F: CCAAGGAAACGTCCACAGTCAG } \\
\text { R: ACGGCTGAAGACATCCTGTCTC }\end{array}$ \\
\hline
\end{tabular}

$B M P 1$, bone morphogenetic protein 1; CCNE2, cyclin E2; CCNG1, cyclin $\mathrm{G} 1 ; C D C 20$, cell division cycle $20 ; C D C 25 C$, cell division cycle 25C; F, forward; $F G F 1$, fibroblast growth factor $1 ; I G F 1$, insulin like growth factor 1; MYC, MYC proto-oncogene, bHLH transcription factor; $P L K 1$, polo like kinase 1; R, reverse.

Multi-class classification. The random variance model (RVM) F-test, which is commonly used to compare $>2$ groups, was applied to filter the differentially expressed genes for the control and experimental groups, since the RVM F-test effectively increases the degrees of freedom in cases of small samples. After analysis of significance and false discovery rate (FDR) analysis using BRB-ArrayTools version 3.0 [http://linus.nci.nih.gov/ BRB-ArrayTools.html (10)], the differentially expressed genes were selected according to the $\mathrm{P}$-value threshold ( $\mathrm{P}$-value $<0.05$, FDR $<0.05$, fold change $\geq 1.5)(10-12)$.

Cluster analysis. Genesis suite was used for cluster analysis (13). The hierarchical clustering tab was used for hierarchical clustering of the data in the present study. Hierarchical clustering is a powerful and useful method used to analyze large genomic datasets. Cluster analysis performs four types of binary, agglomerative and hierarchical clustering. The basic aim is to assemble a set of items (genes or arrays) into a tree, where similar items are joined through short branches and increasingly longer branches as the similarity between items decreases. The first step in hierarchical clustering is to calculate the distance matrix between the gene expression data. Once this matrix of distances is computed, clustering is initiated. Agglomerative hierarchical processing includes repeated cycles, where the two closest remaining items (those with the smallest distance) are joined by a node/branch of a tree, with the length of the branch set to the distance between the joined items. The two joined items are removed from a list of items processed and replaced by an item that represents the new branch. The distances between this new item and all other remaining items are computed, and the process is repeated until only a single item remains.

GO analysis. GO analysis was applied to analyze the main function of the differentially expressed genes according to GO, which is the key functional classification of the National Centers for Biotechnology Information that organizes genes into hierarchical categories and can be used to identify the gene regulatory network on the basis of biological process and molecular function $(14,15)$.

Specifically, two-side Fisher's exact test and $\chi^{2}$ test were used to classify the GO category, and the FDR (16) was calculated to correct the P-value; the smaller the FDR, the smaller the error in judging the P-value. The FDR was defined as FDR $=1-N_{k} / T$, where $N_{k}$ refers to the number of Fisher's test P-values less than $\chi^{2}$ test P-values. P-values were computed for the GO terms of all the differentially expressed genes. Enrichment provides a measure of the significance of the function; as the enrichment increases, the corresponding function is more specific, which helps to identify the GO terms with more concrete functions in the experiment. Within the significant category, the enrichment Re was given by: $\operatorname{Re}=\left(n_{f} / n\right) /\left(N_{f} / N\right)$ where ' $n_{f}$ ' is the number of flagged genes within the particular category, ' $n$ ' is the total number of genes within the same category, ' $N_{f}$ ' is the number of flagged genes in the entire microarray, and ' $N$ ' is the total number of genes in the microarray (17).

Pathway analysis. Pathway analysis was used to identify the significant pathways of the differentially expressed genes according to Kyoto Encyclopedia of Genes and Genomes [KEGG (18-20)], Biocarta $(19,20)$ and Reactome (20). Fisher's exact test and the $\chi^{2}$ test were used to select the significant pathways, and the threshold of significance was defined according to the P-value and FDR. The enrichment Re was calculated as aforementioned (18-20).

STC analysis. According to the RVM corrective analysis, differentially expressed genes were selected at a logical sequence. In accordance with the different signal density alteration tendencies of genes under different situations, a set of unique model expression tendencies were identified. The raw expression values were converted into a $\log 2$ ratio. Using a strategy for clustering short time-series gene expression data, some unique profiles were defined. The expression model profiles are associated with the actual or expected number of genes assigned to each model profile. Significant profiles have higher probability than expected according to Fisher's exact test and multiple comparison tests $(21,22)$.

Signal-net analysis. The gene-gene interaction network was constructed based on the data for differentially expressed genes. Using Java (23), which enables users to build and analyze molecular networks, the network maps were constructed. For example, if there was confirmatory evidence that two genes interacted, then an interaction edge was assigned between the two genes. The considered evidence included the source of the interaction database from KEGG. The networks were stored and presented as graphs, where the nodes primarily repre- 
A

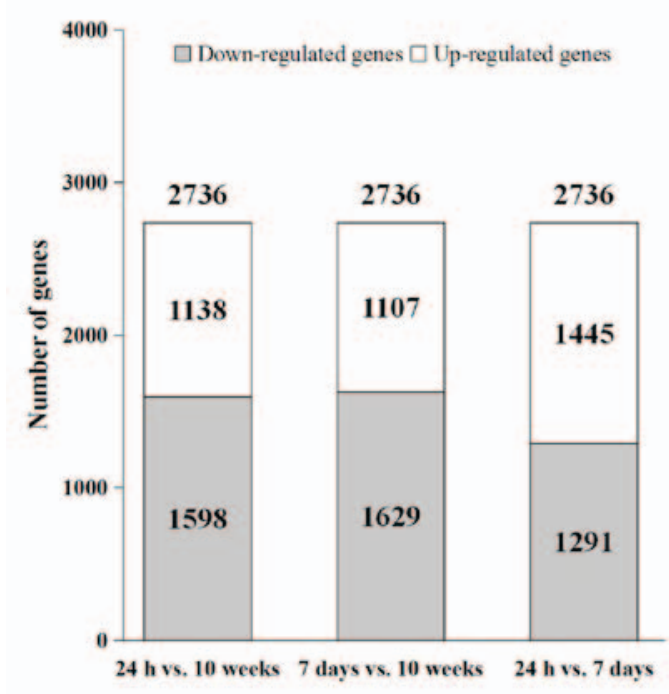

B

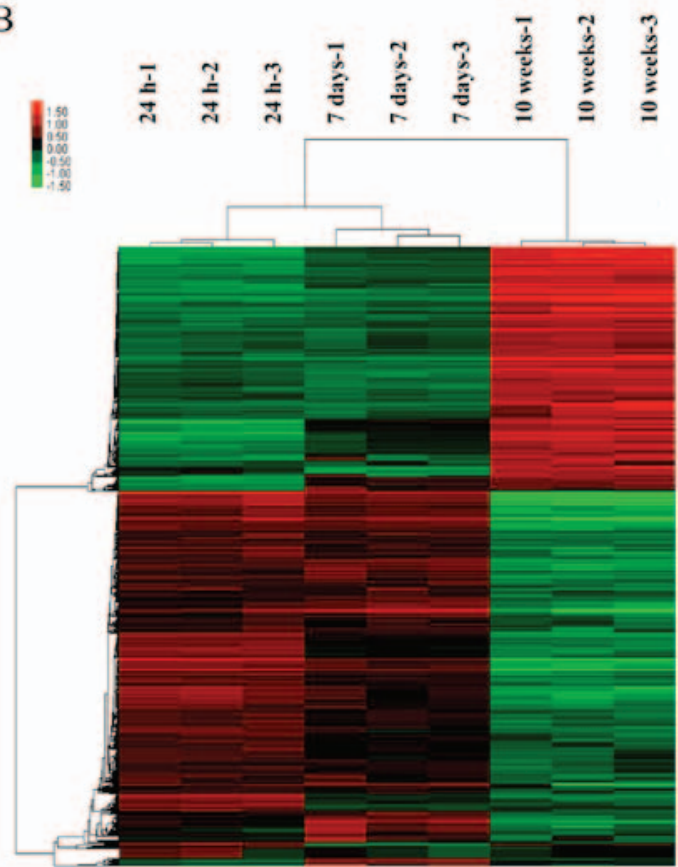

Figure 1. Gene expression profiling of hearts obtained from 24-h-, 7-day- and 10-week-old mice. (A) Differentially expressed genes between the three time-points; there were 1,138 upregulated genes and 1,598 downregulated genes in the 24-h group vs. the 10-week group; 1,107 upregulated genes and 1,629 downregulated genes in the 7-day group vs. the 10-week group; and 1,445 upregulated genes and 1,291 downregulated genes in the 24-h group- vs. the 7-day group. (B) Hierarchical clustering of differentially expressed genes. The abscissa represents the sample, and the ordinate represents the different genes. Red indicates high gene expression, whereas green indicates low gene expression.

sent genes (protein, compound, etc.) and the edges represent relation types between the nodes, e.g., activation or phosphorylation. The networks were examined using the powerful tools implemented in R (24).

To investigate the global network, the most important nodes were identified. To this end, connectivity, also known as degree, was defined as the sum of connection strengths between the network genes:

$$
K_{i}=\sum_{u=i} a_{u i}
$$

where $\mathrm{K} i$ is the sum of connection strengths between the network genes; $\mathrm{a}_{u i}$ represents the weight relations between gene $i$ and gene $j$.

In gene networks, connectivity measures how correlated a gene is with the other network genes. For a gene in the network, the number of source genes of a gene is known as the in-degree and the number of target genes of a gene is known as the out-degree. The character of genes is described using 'betweenness' and centrality measures, which reflect the importance of a node in a graph relative to other nodes. For a graph G:(V, E) with n vertices, the relative 'betweenness' centrality $C_{B}^{\prime}(V)$ is defined according to the following equation:

$$
C_{B}^{\prime}(v)=\frac{2}{n^{2}-3 n+2} \sum_{\substack{s \neq v \pm t \in V \\ s \neq t}} \frac{\sigma_{s t}(v)}{\sigma_{s t}}
$$

where $\sigma_{s t}$ is the number of shortest paths from s to t, and $\sigma_{s t}(V)$ is the number of shortest paths from $s$ to that pass through a vertex v (24-28).

\section{Results}

Global gene expression analysis of 24- $h$-, 7-day-and 10-week-old mouse hearts. Affymetrix Mouse Gene 1.0 ST microarray chips were used to generate the transcriptome profiles of 24-h-, 7-dayand 10-week-old mouse hearts, and 35,557 transcripts were presented in the global gene expression profiles. To reduce selection bias, the RVM was used to modify the F-test to calculate the level of significant difference (P-value), and the FDR was used to obtain the differentially expressed genes. A total of 2,736 differentially expressed genes were selected according to the threshold of $\mathrm{P}<0.05$, FDR $<0.05$, and fold-change $\geq 1.5$ in 24-h-, 7-day- and 10 -week-old mouse hearts. A comparison between 24 -h- and 7-day-old mouse hearts demonstrated a larger proportion of upregulated genes (1,445 upregulated genes vs. 1,291 downregulated genes), whereas the other pairwise comparisons of the groups (24-h- vs. 10-week-old hearts and 7-day- vs. 10-week-old hearts) revealed that the downregulated genes accounted for the majority of expression alterations (Fig. 1A). Using the hierarchical clustering tab, a clear separation between 24-h-, 7-day- and 10-week-old mouse heart samples was observed among the 2,736 differentially expressed transcripts (Fig. 1B). These results suggested that the differences between the three groups were predominant, and not strongly affected by biological variations and differences within the groups. Therefore, 2,736 differentially expressed genes, accounting for $7.69 \%$ of the 35,557 identified transcripts, were selected for further analysis.

Significant functional annotation of the differentially expressed genes. To understand the significant functional alterations in the differentially expressed genes, a GO analysis was conducted, which matches the functional annotation to each gene based on cellular component, molecular function and biological process. Subsequently, using Fisher's test and multiple comparison tests, the P-value (significance level) of each functional annotation was obtained. The standard of significant screening was set at 

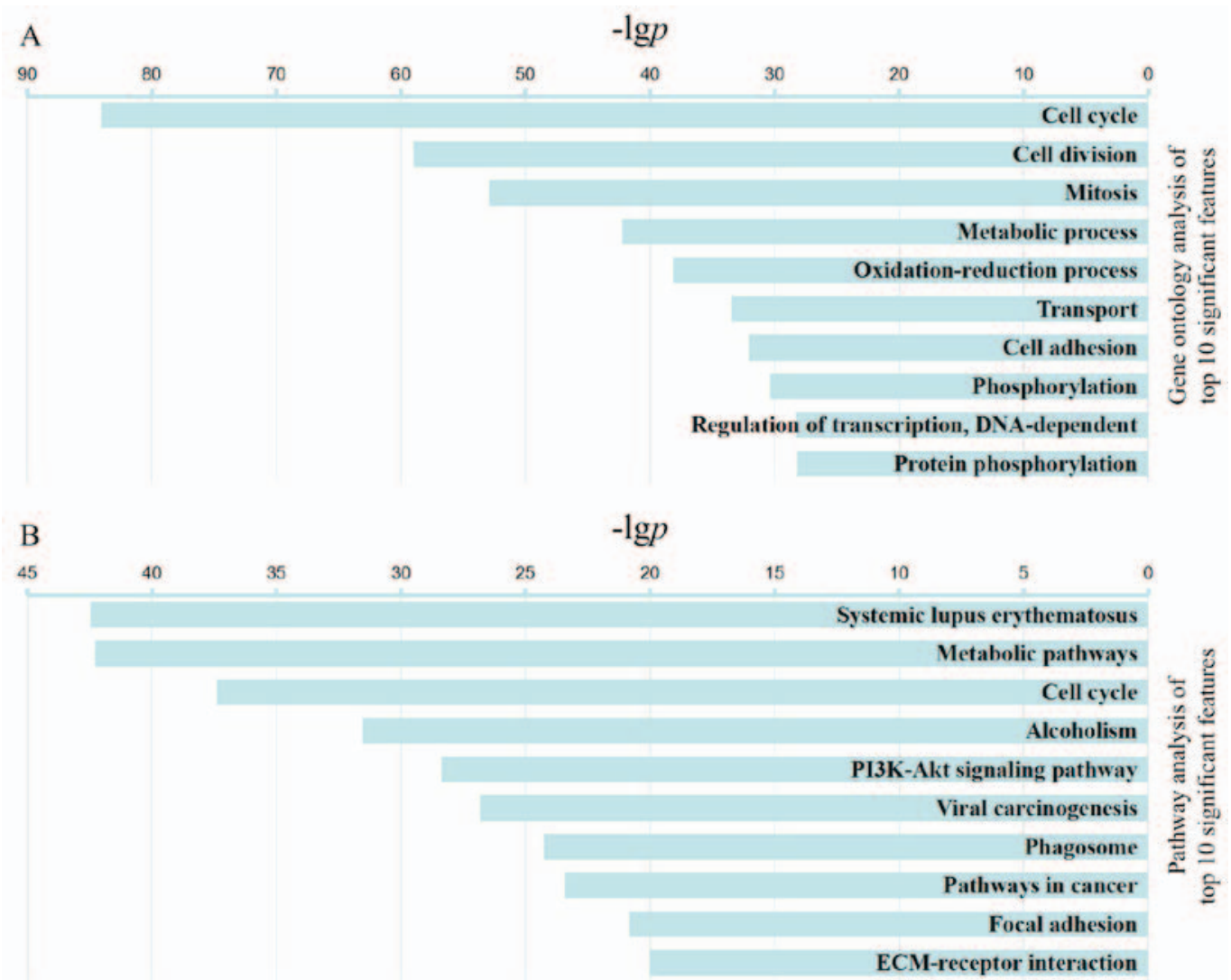

Figure 2. Top 10 significant GO functions ( $\mathrm{P}<6 \mathrm{E}-29$, FDR $<3 \mathrm{E}-26)$ and pathways $(\mathrm{P}<10 \mathrm{E}-21$, FDR $<2.5 \mathrm{E}-19)$. (A) Representative GO annotations. With increasing age, the following enriched GO categories were identified: 'cell cycle', 'cell division', 'mitosis', 'metabolic process', 'oxidation-reduction process', 'transport', 'cell adhesion', 'phosphorylation', 'regulation of transcription, DNA-dependent' and 'protein phosphorylation'. (B) Representative pathways. With increasing age, the following enriched pathway categories were identified; 'systemic lupus erythematosus', 'metabolic pathways', 'cell cycle', 'alcoholism', 'PI3K-AKT signaling pathway', 'viral carcinogenesis', 'phagosome', 'pathways in cancer', 'focal adhesion' and 'ECM-receptor interaction'. The -lgp is displayed on the $\mathrm{x}$-axis. The greater the -lgp, the higher the significance. GO, Gene Ontology; KEGG, Kyoto Encyclopedia of Genes and Genomes.

$\mathrm{P}<0.001$. A total of 357 significant categories were identified from the GO analysis. The top 10 categories are presented in Fig. 2A. The results demonstrated that with increasing age, the differentially expressed genes were involved in 'cell cycle', 'cell division', 'mitosis', 'metabolic process', 'oxidation-reduction process', 'regulation of transcription, DNA-dependent', and 'protein phosphorylation'. These results indicated that the progressive loss of proliferative potential of cardiomyocytes reflects multifunctional and multisystem co-regulation.

Signal transduction pathways associated with the differentially expressed genes. Using KEGG, Biocarta and Reactome databases, the pathways were identified according to systematic relationships, functions and genomic information of the differentially expressed genes. Fisher's test and the $\chi^{2}$ test were used to calculate the P-values, in order to identify the significant signal transduction pathways. A total of 161 significant pathways were identified in the pathway analysis $(\mathrm{P}<0.05)$. The 10 most significant pathways are listed in Fig. 2B, including classical 'cell cycle', and proliferation pathways, including 'PI3K-AKT signaling pathway'. 'metabolic pathways' and 'alcoholism'. In addition, pathways associated with the immune system were significantly enriched, which included 'systemic lupus erythematosus', 'viral carcinogenesis', 'phagosome' and 'focal adhesion'. In addition, the 'ECM-receptor interaction' pathway, which is associated with structural and biochemical support for cardiomyocytes, was also enriched. These findings indicated that postnatal cardiac development is a complex regulatory network associated with numerous proliferative, metabolic and immune-associated pathways.

Analysis of gene expression tendency. STC was used to analyze the differentially expressed genes, in order to accurately and intuitively visualize the genes with the same expression tendency between 24-h-, 7-day- and 10-week-old mouse hearts. Using a significance threshold of $\mathrm{P}<0.05$, differentially expressed genes were grouped into five significant patterns (Fig. 3). In profile 1, which contained 169 genes, gene expression was significantly increased in 7 day hearts compared with in $24 \mathrm{~h}$ hearts, and was markedly decreased compared with in 10 week hearts (Fig. 3A). In profile 2, which contained 898 genes, there was no obvious difference between the $24 \mathrm{~h}$ and 7 day hearts; however a significant decrease in expression was observed in 10 week hearts (Fig. 3B). Profile 3, which contained 254 genes, exhibited continuously decreasing expression from $24 \mathrm{~h}$ to 7 day to 10 week hearts (Fig. 3C). Conversely, profile 4, which included 280 genes, exhibited continuously increasing expression from $24 \mathrm{~h}$ to 7 day to 10 week hearts (Fig. 3D). In profile 5, which contained 625 genes, there was no significant difference in gene expression between the $24 \mathrm{~h}$ and 7 day hearts, whereas much higher expression was observed in 10 week hearts (Fig. 3E). 
A

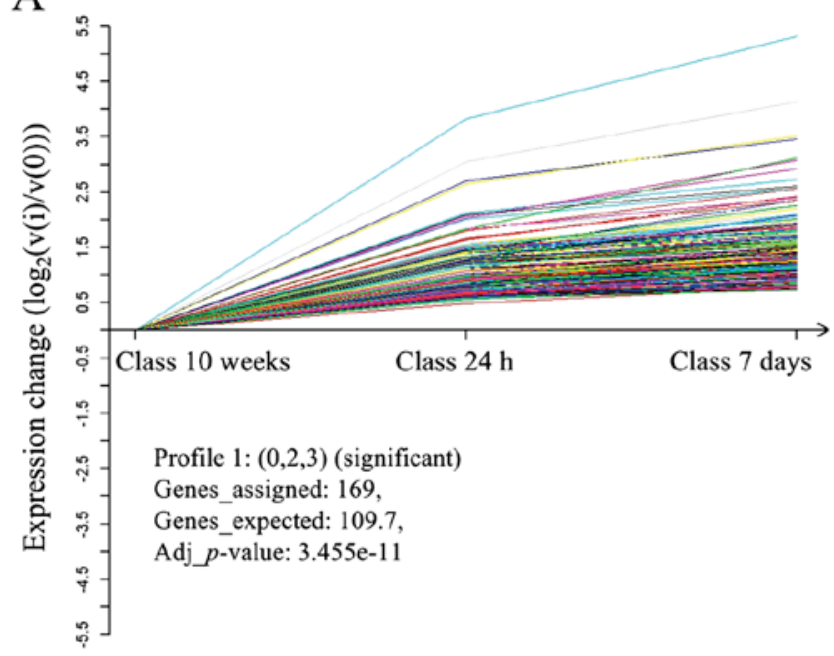

$\mathrm{C}$

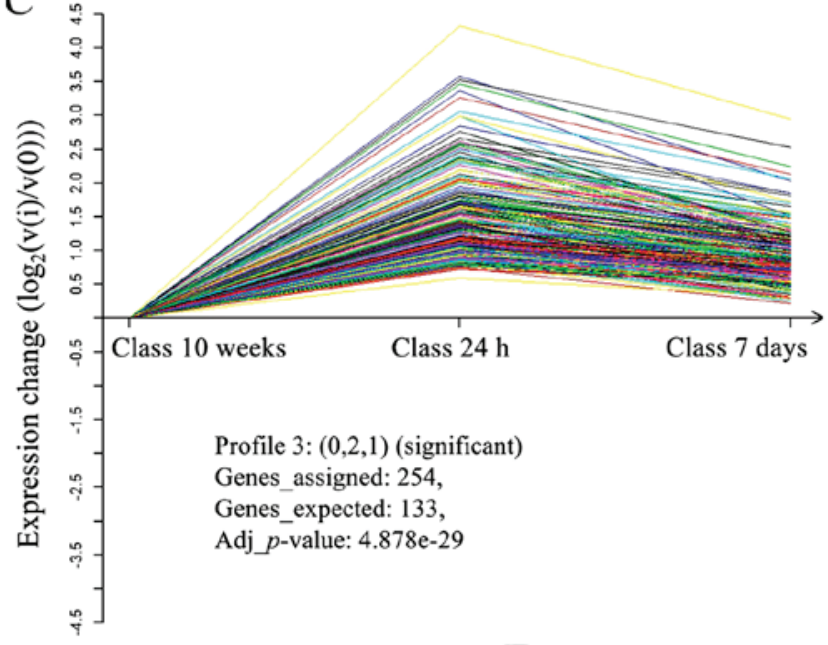

$\mathrm{B}$

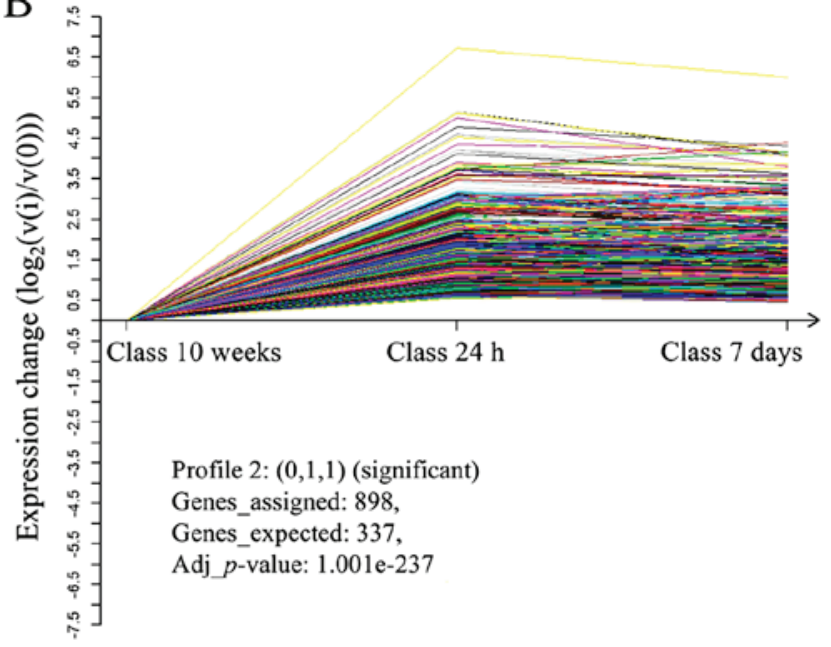

$\mathrm{D}$

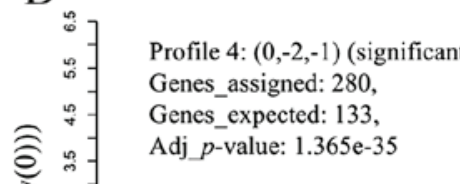

Class 10 weeks Class $24 \mathrm{~h} \quad$ Class

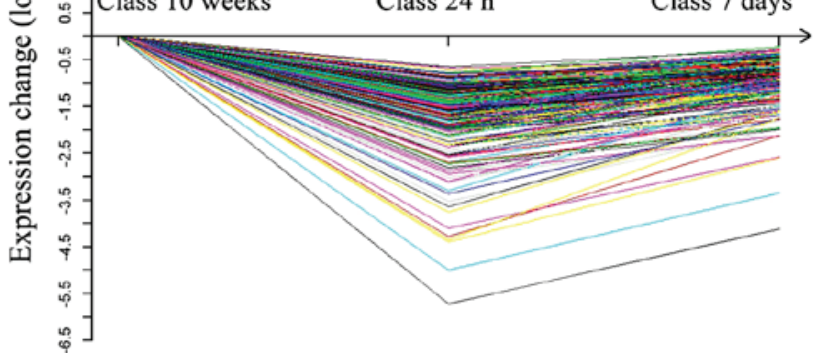

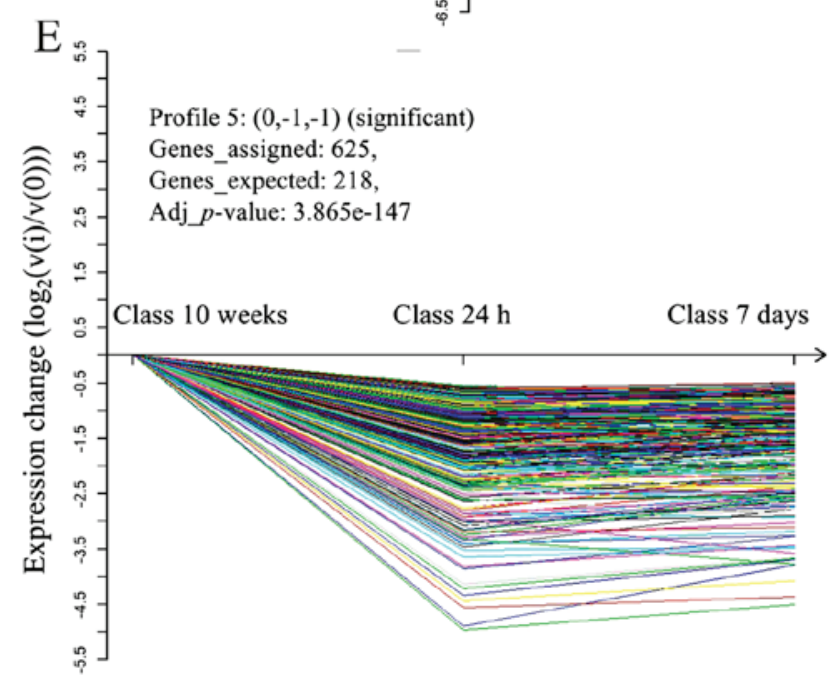

Figure 3. Five significant trends summarized by the model profile. Each profile indicates an expression pattern. The horizontal axis represents time-points, and the vertical axis indicates the time series of gene expression levels for the gene after log-normalized transformation. The value in brackets after the profile represents the variation intensity, the genes assigned represent the gene number in each profile, and the genes expected represent the theoretical gene number in each profile. The P-value represents the significance level between the actual number of genes and the random distribution of genes in theory. (A) Profile 1 shows the contra-regulation pattern. (B) Profile 2 shows the downregulation pattern after 7 days. (C) Profile 3 shows the downregulation pattern. (D) Profile 4 shows the upregulation pattern. (E) Profile 5 shows the upregulation pattern after 7 days.

These five significant patterns indicated that the genes were involved in dynamic activation in 24-h-old mouse hearts, which contain proliferative cardiomyocytes; 7-day-old mouse hearts, which contain cardiomyoctes undergoing a proliferative burst; and 10-week-old mouse hearts, which contain growth-arrested cardiomyocytes. The dynamically regulated 


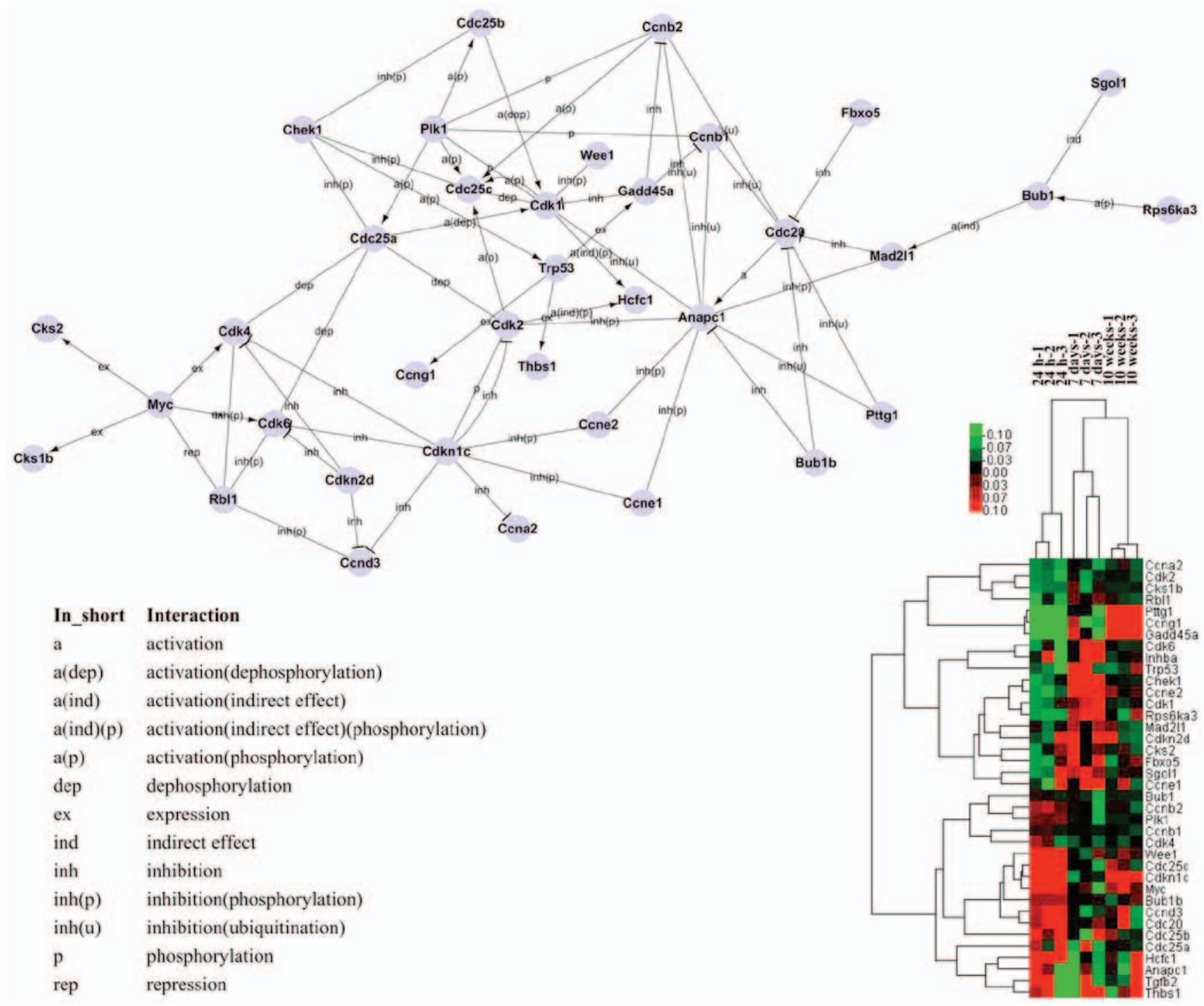

Figure 4. Cell cycle signal transduction pathway and hierarchical clustering of associated genes. Genes associated with the cell cycle were identified through signal-net construction. Cycle nodes represent the genes, and the edges between two nodes represent interactions between genes (arrowheads represent targets). The more edges of a gene indicates that more genes are connected with it, thus suggesting it has a more central role within the network.

genes included the cyclin genes [downregulated, cyclin $(C C N)$ $A 2, C C N B 1, C C N B 2, C C N D 3$ and $C C N E 1$; upregulated, $C C N G 1]$, the genes encoding cyclin-dependent kinases (CDKs) (downregulated, $C D K 1, C D K 2, C D K 4$ and $C D K 6$; upregulated, $C D K 18$ ), downregulated cell cycle-related genes [cell division cycle $(C D C) 20, C D C 25 A$ and $C D C 25 B]$, and downregulated transcription factor genes [MYC proto-oncogene, bHLH transcription factor $(M Y C)$ and $\mathrm{E} 2 \mathrm{~F}$ transcription factor 1 $(E 2 F 1)]$. In addition, growth factor genes [downregulated bone morphogenetic protein (BMP)1,BMPRla, BMP2, BMP5, $B M P 7, B M P 10, I G F 1, I G F 2$ and $I G F 2 R$; upregulated $B M P 6$, fibroblast growth factor $(F G F) 1$ and $F G F 2]$, downregulated mitotic checkpoint serine/threonine-protein kinase genes [BUB1 mitotic checkpoint serine/threonine kinase $(B U B 1)$ and $B U B 1 B]$ and downregulated CDK-interacting protein/kinase inhibitory protein genes [CDK inhibitor $(C D K N) 1 C, C D K N 2 D$ and $C D K N 3]$ were also well enriched. The gene encoding checkpoint kinase 1 (CHEKI), which interacts with numerous downstream effectors to induce cell cycle arrest, was also downregulated in 10-week-old group. Notably, the expression of
$B M P 1, B M P 10, C C N E 2, E 2 F 1$ and $I G F 1$, which were involved in profile 1, peaked in hearts obtained from 7-day-old mice, which was consistent with the findings of Naqvi et al (6).

Signal-net analysis and cell cycle signal transduction network. Signal-net analysis, based on the KEGG database of interactions between different gene products and the theory of network biology, was established to illustrate the inter-gene signaling between the differentially expressed genes. To specifically assess gene interaction, 38 genes were used to construct the cell cycle signal transduction network $(0.11 \%$ of all tested genes; the genes selected were the genes involved in the annotations and pathways related to 'cell cycle', selected based on the GO and pathway analyses) (Fig. 4). The majority of these genes were involved in profile 2 , including classical cell cycle genes, such as cyclin genes (CCNA2, CCNB1, CCNB2 and $C C N E 1)$, genes encoding CDKs (CDK1, CDK2, CDK4 and $C D K 6), C D K N 2 D$, genes encoding the cyclin-dependent kinase regulatory subunit $[\mathrm{CDC} 28$ protein kinase regulatory subunit $(C K S) 1 b$ and $C K S 2$ ], and cell cycle-associated genes 

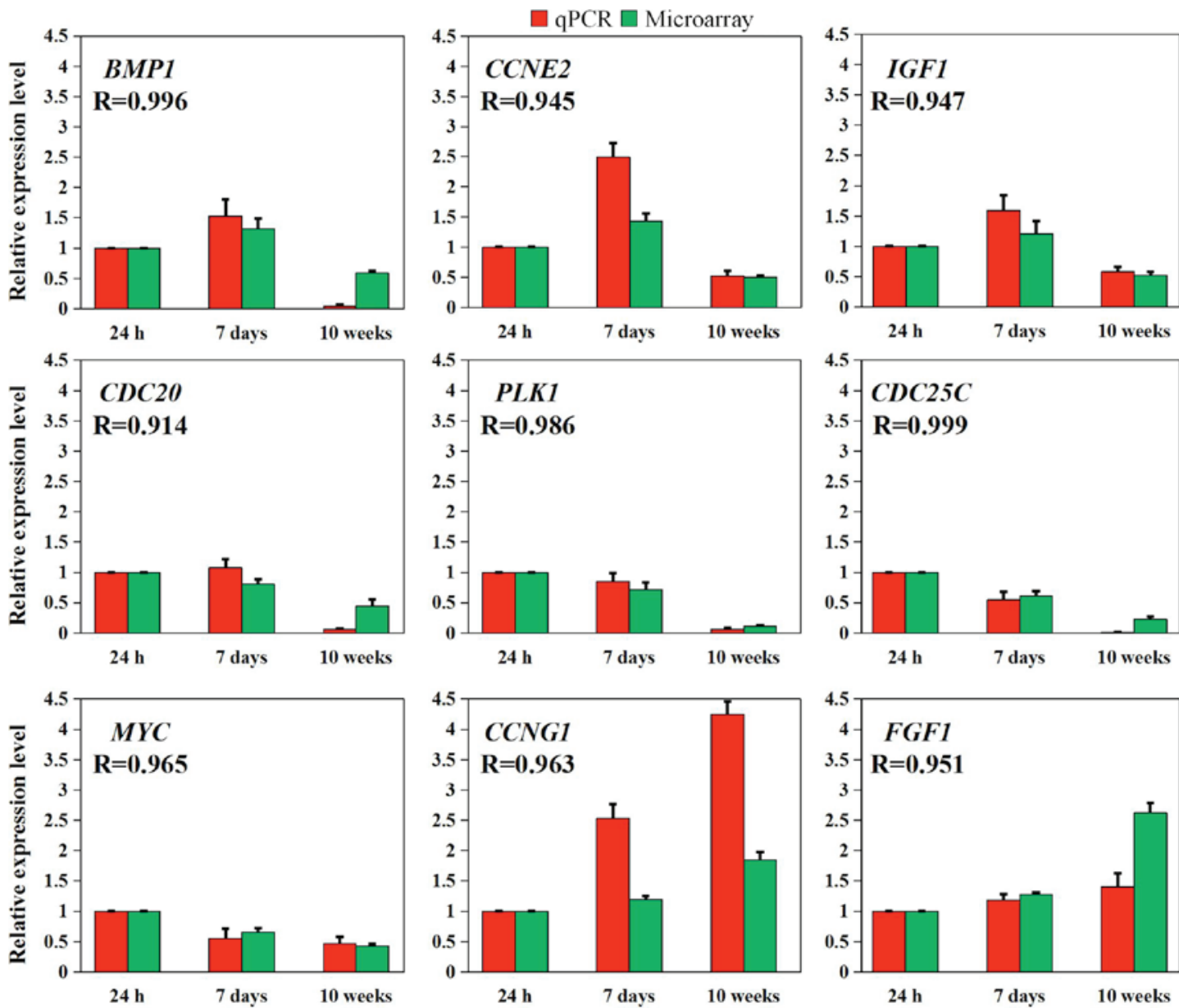

Figure 5. Nine representative differentially expressed genes validated using RT-qPCR. The relative expression levels of the nine genes detected using RT-qPCR (red box) were consistent with the results of the normalized microarray (green box) based on Pearson's correlation analysis $(\mathrm{R}>0.9, \mathrm{P}<0.05)$. The data are expressed as the mean \pm standard error of the mean of three independent experiments. BMP1, bone morphogenetic protein 1; CCNE2, cyclin E2; CCNG1, cyclin G1; CDC20, cell division cycle 20; CDC25C, cell division cycle 25C; FGF1, fibroblast growth factor 1; IGF1, insulin like growth factor 1; MYC, MYC proto-oncogene, bHLH transcription factor; PLK1, polo like kinase 1; R, Pearson's correlation coefficient; RT-qPCR, reverse transcription-quantitative polymerase chain reaction.

(CDC20, CDC25A and $C D C 25 B)$. The genes encoding cell cycle checkpoints, regulators and growth factors, including $B U B 1, B U B 1 B, C H E K 1$, anaphase promoting complex subunit 1 (ANAPC1), mitotic arrest deficient 2 like 1, polo like kinase 1 (PLK1), RB transcriptional corepressor like 1 (p107), transformation related protein 53 , shugosin 1 , ribosomal protein S6 kinase A3, transforming growth factor- $\beta 2$ (TGF- $\beta 2)$ and thrombospondin 1, were also enriched in this network. The genes involved in profile 5, including growth arrest and DNA-damage-inducible protein $45 \alpha(G A D D 45 \alpha)$ and pituitary tumor-transforming 1 (PTTG1; APC substrate); profile 3, including $C D C 25 C, C C N D 3, C D K N 1 C$, WEE1 G2 checkpoint kinase (Cdk1 inhibitor), $M Y C$ (transcription factor), and host cell factor $\mathrm{C} 1$ (transcription factor); profile $4(C C N G 1)$; and profile 1 (CCNE2) were also well enriched. Notably, in the network, the genes with higher degree (interactive ability), including $A N A P C 1, C D C 20, C D K 1, M Y C$ and $C D C 25 C$, may serve important roles in myocardial cell cycle arrest from 7 days to 10 weeks. In the network, $A N A P C 1$, which inhibits CCNB1, CCNB2, CDK1 and PTTG1 through ubiquitination, was activated through $C D C 20 . C D C 20$ also inhibited $C C N B 1$ and $C C N B 2$ through ubiquitination. $C D C 25 C$ achieved its function through the dephosphorylation of $C D K 1$. These data indicated that the regulation of these five genes (ANAPCl, $C D C 20, C D K 1, M Y C$ and $C D C 25 C$ ) may induce cardiomyocytes to maintain proliferative capacity after preadolescence. Furthermore, in the network, $G A D D 45 \alpha$ is likely to inhibit the expression of $C C N B 1$ and $C C N B 2$, and $C D K 1$ may regulate myocardial cell cycle at birth.

$R T-q P C R$ verification of gene expression. RT-qPCR was used to examine nine representative genes, including $B M P 1$, $C C N E 2$ and $I G F 1$ from profile $1, C D C 20$ and $P L K 1$ from profile 2, CDC25C and MYC from profile 3, CCNG1 from profile 4 and $F G F 1$ from profile 5, to validate the microarray data. As presented in Fig. 5, these results were consistent with the normalized microarray data, based on either fold changes in expression and/or potential functions.

\section{Discussion}

Mammalian cardiomyocytes retain relatively high proliferative potential at birth, which gradually diminishes after a few days as a result of myocardial cell cycle arrest (29-31). Furthermore, 
during adolescence, a burst of proliferation occurs in cardiomyocytes (6). However, the alterations in gene expression during the critical period from birth to adolescence and then to adulthood remain unknown. To elucidate the molecular mechanism and the gene expression alterations that occur during this key period, the present study conducted global gene expression profiling to generate transcriptomes from 24-h-, 7-day- and 10-week-old C57BL/6 mouse hearts. These time-points reflect the phases of proliferative activation, proliferative burst and proliferative arrest, respectively. In addition, GO annotation, STC, pathway enrichment and network construction were conducted to identify the state of cardiomyocytes from numerous perspectives.

As expected, the GO analysis revealed that, with increasing age, the expression of genes involved in the cell cycle, cell division and mitosis, as well as metabolic process, protein synthesis and protein modification was significantly altered. These results were highly consistent with the findings of the pathway analysis, which indicated that the phosphoinositide 3-kinase (PI3K)-protein kinase B (AKT) signaling pathway was enriched. These findings indicated that the cell cycle and protein modification are important in postnatal mouse heart development. Numerous proliferative stimulators directly activate the PI3K-AKT pathway by promoting nuclear translocation, and increasing the phosphorylation and degradation of proteins associated with myocardial proliferation (32). The progressive loss of proliferative potential in cardiomyocytes reflects multifunctional and multisystem co-regulation. In addition, pathways associated with the immune system were enriched, reflecting the fact that neonatal mice are undergoing a transition from reliance on the intrauterine physiological environment to self-sufficiency. Following birth, the immune system faces the challenge of transferring from a sterile environment to a microbe-containing environment (33).

Notably, in the present study the differentially expressed genes were grouped into five patterns, according to the relative expression of the differentially expressed genes at three different time-points. Specifically, the majority of cyclin genes (CCNA2, CCNB1, CCNB2 and CCNE1), CDK genes $(C D K 1, C D K 2, C D K 4$ and $C D K 6)$ and cell cycle-related genes $(C D C 20, C D C 25 A$ and $C D C 25 B)$ were involved in profile 2 . In addition, cyclin genes (CCNE2) and growth factors, including $B M P 1, B M P 10, E 2 F 1$ and $I G F 1$, were involved in profile 1, which exhibited a burst of increased expression in 7-day-old hearts. These genes may increase mice myocardial proliferative potential within 7 days of age and could potentially elicit myocardial proliferation in damaged adult hearts. These data were consistent with the findings of Naqvi et al, which generated a molecular model of myocardial proliferation involving thyroid hormones and the IGF1/AKT pathway (6). In addition, Rochais et al reported that $I G F 1$ regulated activation of the PI3K/AKT pathway to downregulate the expression of p21 and p27 in proliferating cardiomyocytes (34). BMP1 is essential for normal heart development; also this gene serves non-redundant roles in the genetic and morphogenetic processes in human congenital heart disease (35). Furthermore, BMP10 is essential for maintaining cardiac growth during murine cardiogenesis (36). Although E2Fs promote S-phase entry and DNA synthesis, Ebelt et al reported that $\mathrm{E} 2 \mathrm{~F} 1$ promotes mitotic cell division by increasing the expression of cyclin B1 and B2 in neonatal cardiomyocytes (37). Therefore, these genes are likely to be involved in the burst of cardiomyocyte proliferation during early preadolescence. Theoretically, stimulating the expression of these genes may increase proliferative capacity in post-adolescent and adult hearts.

To date, some critical genes, including $B U B 1$, dynein light chain Tctex-type 1A (DYNLT1 $\alpha)$, tropomodulin 4 (TMOD4) and glutamate metabotropic receptor 1 , which were screened in the present study, have not been described in the context of myocardial proliferation. However, in other tissues, these genes serve regulatory roles in cell proliferation. Bieniek et al reported that the marked downregulation of key proteins in kinetochore/centromere assembly, including Cdc20, Ndc80, Bub1 and Plk1, may arrest prostate cancer proliferation (38). Yeh et al reported that DYNLT1 $\alpha$ encodes Tctex-1, which is involved in the IGF1R-Gbg-phospho (T94) Tctex-1 signaling pathway and promotes the proliferation of neural progenitors via the modulation of ciliary resorption and $\mathrm{G}_{1}$ length (39). Berger et al reported that loss of the Tmod4 protein may cause cytoplasmic rod formation and muscle weakness reminiscent of nemaline myopathy in zebrafish (40). Therefore, it may be hypothesized that these genes serve important roles in myocardial proliferation.

Notably, genes associated with progenitor cells, pluripotent stem cells and fibroblasts were also well enriched in the present study. A previous study confirmed that cardiac progenitor cells reside in postnatal hearts (41). These genes were identified using the expression of surface markers, such as c-Kit $(42,43)$, which was encoded by KIT and was downregulated in the present study. BMP genes (BMP1, BMP5, BMP7, BMP10 and BMPRla), which are required for the optimization of efficient cardiac differentiation from pluripotent stem cells, were also downregulated in the present study (44). Fibroblasts and myofibroblasts secrete collagens (encoded by COL genes), which function as primary structural proteins and provide mechanical support (45). Collagens can be degraded by matrix metalloproteinases $(M M P s)$, which are a group of endopeptidases, thus enabling cell migration into the injured area (46). MMPs are inhibited via the tissue inhibitors of metalloproteinases (TIMP) family, which is associated with extracellular matrix (ECM) expansion and cardiac fibrosis (47). In the present study, $C O L$ genes, $M M P$ genes (MMP2, MMP14 and MMP16) and TIMP1 were downregulated. The homeostasis of ECM factors, which exhibited a similar expression trend between 24-h- and 10-week-old hearts, provides a perfect scaffold for all cardiomyocytes. In addition, the 'ECM-receptor interaction' pathway was enriched in the pathway analysis. Other factors associated with cardiac fibrosis were also well enriched; $T G F \beta-2, F G F 12, F G F R 2$ and platelet derived growth factor $(P D G F) A$ were continuously decreased after birth, whereas FGF1, FGF2, FGF7, FGF16 and PDGFD were highly expressed in 10 -week-old hearts. Considering the fact that at birth, the heart can completely repair its site of injury without scar, whereas fibrotic scar formation occurs in injured adult hearts, the results of the present study may provide a basis for the physiological condition of progenitor cells, pluripotent stem cell differentiation and fibrotic scar formation.

A signal transduction network analysis of the cell cycle was used to efficiently investigate the phenomenon of myocardial cell cycle arrest. The results suggested that ANAPC1, CDC20, $C D K 1, M Y C, C D C 25 C$ and $G A D D 45 \alpha$, which exhibited the 
stronger interactive abilities within the network, may serve important regulatory roles in myocardial cell cycle arrest. In the network, ANAPC1 inhibited the expression of $C C N B 1, C C N B 2$, $C D K 1$ and $P T T G 1$ through ubiquitination, and was activated by $C D C 20$, which also inhibited the expression $C C N B 1$ and $C C N B 2$ via ubiquitination. A previous study reported that $\mathrm{APC} /$ cyclosome $(\mathrm{C})$ regulates the ubiquitin-dependent proteolysis of specific cell-cycle proteins to coordinate chromosome segregation in mitosis and entry into the $G_{1}$ phase (48). The catalytic activity of the $\mathrm{APC} / \mathrm{C}$ and its ability to initiate the destruction of particular proteins at different phases of the cell cycle are controlled through interactions with the structurally related coactivator subunit, $\mathrm{Cdc} 20$. In cardiomyocytes, blocking APC/C $C^{\mathrm{Cdc} 20}$ may lead to $\mathrm{G}_{2}$ arrest (49). These findings are also consistent with the data from the GO and pathway analyses. $A N A P C 1$ and $C D C 20$ shared the same functional annotation, which included cell cycle, cell division and mitosis, and both participate in cell cycle and ubiquitin-mediated proteolysis pathways. These genes were involved in profile 2, which exhibited downregulation from 7 days to 10 weeks of age. Together, these results suggested that $A N A P C 1$ and $C D C 20$ may have important roles in the phenomenon of myocardial cell cycle arrest from early puberty to adulthood.

In the network, $C D C 25 C$ was activated through the dephosphorylation of $C D K 1$, which activates $C D C 25 C$ by phosphorylation. Consistent with a previous study by Forester et al, Cdk1 activity is controlled through the phosphatase $\mathrm{Cdc} 25 \mathrm{C}$, which is turned on at the $\mathrm{G}_{2} / \mathrm{M}$ transition to catalyze Cdk1 activation (50). This constitutive activation of Cdc25C and Cdk1 leads to a delayed exit from mitosis. Franckhauser et al observed that during mitosis, the nonphosphorylated mutant forms of $C D C 25 C$ impair mitotic progression in human cells (51). In addition, cell cycle, cell division, mitosis and protein phosphorylation were well enriched in $C D K 1$, and $C D K 1$ and $C D C 25 C$ were involved in the cell cycle pathway. $M Y C$ activates $C D K 4$ and $C D K 6$ in the network. Villa Del Campo et al reported that overexpression of MYC increases the population of cardiomyocytes and enhances the epicardial contribution to the developing heart (52). In addition, $\mathrm{GO}$ analysis revealed that $M Y C$ has a large role in the regulation of transcription and participates in the cell cycle, and PI3K-Akt, Hippo, mitogen-activated protein kinase (MAPK) and TGF- $\beta$ signaling pathways in the pathway analysis. These results suggested that $M Y C$ may be involved in various functions, and function as an intermediate mediator of various pathways in myocardial cell cycle arrest. $M Y C$ and $C D C 25 C$ were both involved in profile 3 , which began to decrease in 24-h-old hearts and may initiate regulatory functions in the cell cycle at birth.

In the network, $G A D D 45 \alpha$ inhibited the expression of $C C N B 1, C C N B 2$ and $C D K 1$. GADD $45 \alpha$ serves a role in S-phase and $\mathrm{G}_{2} / \mathrm{M}$ arrest (53). Similarly, Gadd45 $\alpha$ binds Cdk1, likely preventing its association with cyclin B1, inhibiting Cdk1 activity, and arresting the cell at the $\mathrm{G}_{2} / \mathrm{M}$ checkpoint (54). At present, no report has been published regarding the relationship between myocardial cell cycle arrest and GADD $45 \alpha$. However, the results of an in vitro assay of cortical neuron development indicated that overexpression and knockdown of GADD $45 \alpha$ transcription suppressed the formation of distal neurite processes and often promoted aberrantly shaped and sized cell bodies. In addition, overexpression did not affect migration but rather led to irregular and hypertrophied cell body development (55). The results of the pathway analysis in the present study indicated that $G A D D 45 \alpha$ may be involved in the p53 and MAPK signaling pathways, and was the only gene from profile 1 with increased expression at 7 days old. These results suggested that the increased expression of GADD $45 \alpha$ may serve important roles in myocardial cell cycle arrest from early puberty to adulthood.

Gene expression profile analyses have the advantage of generating huge amounts of biological information, which can be objectively filtered and accurately analyzed. The present study used GO annotation, pathway analysis and STC to analyze the specific functions, pathways and logical patterns of the differentially expressed genes. Notably, a potential cell cycle signal transduction network was constructed in the present study. This network enables the screening of the potential genes associated with a single function, the cell cycle. The present study may have value as an important reference concerning the gene expression profile in the heart during proliferation.

\section{Acknowledgements}

The present study was supported by the National Natural Science Foundation of China [grant no. 81570256 (to M.W.)], and the China Scholarship Council [grant no. 201506940022 (to R.W.)]. The authors would like to thank Dongjia Ge for contributing to the design of the figures. The global gene expression data are available at the Gene Expression Omnibus website (https://www. ncbi.nlm.nih.gov/geo/) under accession no. GSE93426.

\section{References}

1. Mozaffarian D, Benjamin EJ, Go AS, Arnett DK, Blaha MJ, Cushman M, Das SR, de Ferranti S, Després JP, Fullerton HJ, et al; Writing Group Members; American Heart Association Statistics Committee; Stroke Statistics Subcommittee: Heart Disease and Stroke Statistics-2016 Update: A Report From the American Heart Association. Circulation 133: e38-e360, 2016.

2. Murry CE, Reinecke H and Pabon LM: Regeneration gaps: Observations on stem cells and cardiac repair. J Am Coll Cardiol 47: 1777-1785, 2006.

3. Linzbach AJ: Heart failure from the point of view of quantitative anatomy. Am J Cardiol 5: 370-382, 1960.

4. Poss KD, Wilson LG and Keating MT: Heart regeneration in zebrafish. Science 298: 2188-2190, 2002.

5. Porrello ER, Mahmoud AI, Simpson E, Hill JA, Richardson JA, Olson EN and Sadek HA: Transient regenerative potential of the neonatal mouse heart. Science 331: 1078-1080, 2011.

6. Naqvi N,Li M, Calvert JW, Tejada T,Lambert JP, Wu J,Kesteven SH, Holman SR, Matsuda T, Lovelock JD, et al: A proliferative burst during preadolescence establishes the final cardiomyocyte number. Cell 157: 795-807, 2014.

7. Mollova M, Bersell K, Walsh S, Savla J, Das LT, Park SY, Silberstein LE, Dos Remedios CG, Graham D, Colan S, et al: Cardiomyocyte proliferation contributes to heart growth in young humans. Proc Natl Acad Sci USA 110: 1446-1451, 2013.

8. Gan J, Sonntag HJ, Tang MK, Cai D and Lee KK: Integrative Analysis of the Developing Postnatal Mouse Heart Transcriptome. PLoS One 10: e0133288, 2015.

9. Livak KJ and Schmittgen TD: Analysis of relative gene expression data using real-time quantitative PCR and the 2(-Delta Delta C(T)) Method. Methods 25: 402-408, 2001.

10. Wright GW and Simon RM: A random variance model for detection of differential gene expression in small microarray experiments. Bioinformatics 19: 2448-2455, 2003.

11. Yang H, Crawford N, Lukes L, Finney R, Lancaster M and Hunter KW: Metastasis predictive signature profiles pre-exist in normal tissues. Clin Exp Metastasis 22: 593-603, 2005.

12. Clarke R, Ressom HW, Wang A, Xuan J, Liu MC, Gehan EA and Wang Y: The properties of high-dimensional data spaces: Implications for exploring gene and protein expression data. Nat Rev Cancer 8: 37-49, 2008. 
13. Eisen MB, Spellman PT, Brown PO and Botstein D: Cluster analysis and display of genome-wide expression patterns. Proc Natl Acad Sci USA 95: 14863-14868, 1998.

14. Gene Ontology Consortium: The Gene Ontology (GO) project in 2006. Nucleic Acids Res 34: D322-D326, 2006.

15. Ashburner M, Ball CA, Blake JA, Botstein D, Butler H, Cherry JM, Davis AP, Dolinski K, Dwight SS, Eppig JT, et al; The Gene Ontology Consortium: Gene ontology: Tool for the unification of biology. Nat Genet 25: 25-29, 2000.

16. Dupuy D, Bertin N, Hidalgo CA, Venkatesan K, Tu D, Lee D, Rosenberg J, Svrzikapa N, Blanc A, Carnec A, et al: Genome-scale analysis of in vivo spatiotemporal promoter activity in Caenorhabditis elegans. Nat Biotechnol 25: 663-668, 2007.

17. Schlitt T, Palin K, Rung J, Dietmann S, Lappe M, Ukkonen E and Brazma A: From gene networks to gene function. Genome Res 13: 2568-2576, 2003.

18. Kanehisa M, Goto S, Kawashima S, Okuno Y and Hattori M The KEGG resource for deciphering the genome. Nucleic Acids Res 32: D277-D280, 2004.

19. Yi M, Horton JD, Cohen JC, Hobbs HH and Stephens RM: WholePathwayScope: A comprehensive pathway-based analysis tool for high-throughput data. BMC Bioinformatics 7 : 30, 2006.

20. Draghici S, Khatri P, Tarca AL, Amin K, Done A, Voichita C, Georgescu C and Romero R: A systems biology approach for pathway level analysis. Genome Res 17: 1537-1545, 2007.

21. Ramoni MF, Sebastiani P and Kohane IS: Cluster analysis of gene expression dynamics. Proc Natl Acad Sci USA 99: 9121-9126, 2002.

22. Miller LD, Long PM, Wong L, Mukherjee S, McShane LM and Liu ET: Optimal gene expression analysis by microarrays. Cancer Cell 2: 353-361, 2002.

23. Dysvik B and Jonassen I: J-Express: exploring gene expressiondata using Java. Bioinformatics 17: 369-370, 2001.

24. Jansen R, Greenbaum D and Gerstein M: Relating whole-genome expression data with protein-protein interactions. Genome Res 12 $37-46,2002$

25. $\mathrm{Li} \mathrm{C}$ and $\mathrm{Li} \mathrm{H}$ : Network-constrained regularization and variable selection for analysis of genomic data. Bioinformatics 24 $1175-1182,2008$.

26. Wei $\mathrm{Z}$ and $\mathrm{Li} \mathrm{H}$ : A Markov random field model for network-based analysis of genomic data. Bioinformatics 23: $1537-1544,2007$

27. Zhang JD and Wiemann S: KEGGgraph: A graph approach to KEGG PATHWAY in R and bioconductor. Bioinformatics 25 1470-1471, 2009

28. Spirin V and Mirny LA: Protein complexes and functional modules in molecular networks. Proc Natl Acad Sci USA 100: 12123-12128, 2003

29. Burton PB, Raff MC, Kerr P, Yacoub MH and Barton PJ: An intrinsic timer that controls cell-cycle withdrawal in cultured cardiac myocytes. Dev Biol 216: 659-670, 1999.

30. Tane S, Kubota M, Okayama H, Ikenishi A, Yoshitome S, Iwamoto N, Satoh Y, Kusakabe A, Ogawa S, Kanai A, et al: Repression of cyclin D1 expression is necessary for the maintenance of cell cycle exit in adult mammalian cardiomyocytes. J Biol Chem 289: 18033-18044, 2014.

31. Tane S, Ikenishi A, Okayama H, Iwamoto N, Nakayama KI and Takeuchi T: CDK inhibitors, p21(Cip1) and p27(Kip1), participate in cell cycle exit of mammalian cardiomyocytes. Biochem Biophys Res Commun 443: 1105-1109, 2014.

32. Lin Z, Zhou P, von Gise A, Gu F, Ma Q, Chen J, Guo H, van Gorp PR, Wang DZ and Pu WT: Pi3kcb links Hippo-YAP and PI3K-AKT signaling pathways to promote cardiomyocyte proliferation and survival. Circ Res 116: 35-45, 2015.

33. Marshall-Clarke S, Reen D, Tasker L and Hassan J: Neonatal immunity: How well has it grown up? Immunol Today 21: 35-41, 2000.

34. Rochais F, Sturny R, Chao CM, Mesbah K, Bennett M, Mohun TJ, Bellusci S and Kelly RG: FGF10 promotes regional foetal cardiomyocyte proliferation and adult cardiomyocyte cell-cycle re-entry. Cardiovasc Res 104: 432-442, 2014

35. Thomas PS, Rajderkar S, Lane J, Mishina Y and Kaartinen V: AcvR1-mediated BMP signaling in second heart field is required for arterial pole development: Implications for myocardial differentiation and regional identity. Dev Biol 390: 191-207, 2014

36. Chen H, Shi S, Acosta L, Li W, Lu J, Bao S, Chen Z, Yang Z, Schneider MD, Chien KR, et al: BMP10 is essential for maintaining cardiac growth during murine cardiogenesis. Development 131: 2219-2231, 2004
37. Ebelt H, Hufnagel N, Neuhaus P, Neuhaus H, Gajawada P, Simm A, Müller-Werdan U, Werdan K and Braun T: Divergent siblings: $\mathrm{E} 2 \mathrm{~F} 2$ and $\mathrm{E} 2 \mathrm{~F} 4$ but not E2F1 and E2F3 induce DNA synthesis in cardiomyocytes without activation of apoptosis. Circ Res 96: 509-517, 2005.

38. Bieniek J, Childress C, Swatski MD and Yang W: COX-2 inhibitors arrest prostate cancer cell cycle progression by downregulation of kinetochore/centromere proteins. Prostate 74: 999-1011, 2014

39. Yeh C, Li A, Chuang JZ, Saito M, Cáceres A and Sung CH: IGF-1 activates a cilium-localized noncanonical $\mathrm{G} \beta \gamma$ signaling pathway that regulates cell-cycle progression. Dev Cell 26: 358-368, 2013

40. Berger J, Tarakci H, Berger S, Li M, Hall TE, Arner A and Currie PD: Loss of Tropomodulin4 in the zebrafish mutant träge causes cytoplasmic rod formation and muscle weakness reminiscent of nemaline myopathy. Dis Model Mech 7: 1407-1415, 2014.

41. Segers VF and Lee RT: Stem-cell therapy for cardiac disease. Nature 451: 937-942, 2008

42. Passier R, van Laake LW and Mummery CL: Stem-cell-based therapy and lessons from the heart. Nature 453: 322-329, 2008.

43. Bearzi C, Rota M, Hosoda T, Tillmanns J, Nascimbene A, De Angelis A, Yasuzawa-Amano S, Trofimova I, Siggins RW, Lecapitaine N, et al: Human cardiac stem cells. Proc Natl Acad Sci USA 104: 14068-14073, 2007.

44. Kattman SJ, Witty AD, Gagliardi M, Dubois NC, Niapour M, Hotta A, Ellis J and Keller G: Stage-specific optimization of activin/nodal and BMP signaling promotes cardiac differentiation of mouse and human pluripotent stem cell lines. Cell Stem Cell 8: 228-240, 2011

45. Horn MA and Trafford AW: Aging and the cardiac collagen matrix: Novel mediators of fibrotic remodelling. J Mol Cell Cardiol 93: 175-185, 2016.

46. Lindsey ML, Iyer RP, Jung M, DeLeon-Pennell KY and Ma Y Matrix metalloproteinases as input and output signals for post-myocardial infarction remodeling. J Mol Cell Cardiol 91: 134-140, 2016.

47. Vanhoutte D and Heymans S: TIMPs and cardiac remodeling: 'Embracing the MMP-independent-side of the family'. J Mol Cell Cardiol 48: 445-453, 2010.

48. Zhang S, Chang L, Alfieri C, Zhang Z, Yang J, Maslen S, Skehel M, Barford D. Molecular mechanism of APC/C activation by mitotic phosphorylation. Nature 533: 260-264, 2016.

49. Yamada K, Tamamori-Adachi M, Goto I, Iizuka M, Yasukawa T, Aso T, Okazaki T and Kitajima S: Degradation of p21Cip1 through anaphase-promoting complex/ cyclosome and its activator $\mathrm{Cdc} 20\left(\mathrm{APC} / \mathrm{C}^{\mathrm{Cdc} 20}\right.$ ) ubiquitin ligase complex-mediated ubiquitylation is inhibited by cyclin-dependent kinase 2 in cardiomyocytes. J Biol Chem 286: 44057-44066, 2011

50. Forester CM, Maddox J, Louis JV, Goris J and Virshup DM: Control of mitotic exit by $\mathrm{PP} 2 \mathrm{~A}$ regulation of $\mathrm{Cdc} 25 \mathrm{C}$ and Cdk1. Proc Natl Acad Sci USA 104: 19867-19872, 2007.

51. Franckhauser C, Mamaeva D, Heron-Milhavet L, Fernandez A and Lamb NJ: Distinct pools of cdc25C are phosphorylated on specific TP sites and differentially localized in human mitotic cells. PLoS One 5: e11798, 2010.

52. Villa Del Campo C, Lioux G, Carmona R, Sierra R, Muñoz-Chápuli R, Clavería C and Torres M: Myc overexpression enhances of epicardial contribution to the developing heart and promotes extensive expansion of the cardiomyocyte population. Sci Rep 6: 35366, 2016.

53. Hollander MC and Fornace AJ Jr: Genomic instability, centrosome amplification, cell cycle checkpoints and Gadd45a. Oncogene 21: 6228-6233, 2002

54. Zhan Q, Antinore MJ, Wang XW, Carrier F, Smith ML, Harris CC and Fornace AJ Jr: Association with Cde2 and inhibition of $\mathrm{Cdc} 2 /$ Cyclin B1 kinase activity by the p53-regulated protein Gadd45. Oncogene 18: 2892-2900, 1999.

55. Sarkisian MR and Siebzehnrubl D: Abnormal levels of Gadd45alpha in developing neocortex impair neurite outgrowth. PLoS One 7: e44207, 2012.

This work is licensed under a Creative Commons Attribution-NonCommercial-NoDerivatives 4.0 International (CC BY-NC-ND 4.0) License. 